associations and by their achievements although it no doubt feels, as the report suggests, that methods of financing may need recasting and particularly that the measure of Government finaneial support is inadequate. It is true that in the past there has been a serious lack of means in Britain to put to their fullest use the results of research. For their part, the research associations have not had in general the means to pursue active development in this respect. This function has been regarded as the responsibility of industry, but it becomes increasingly clear that the large-scale development of important research results must in the future become the responsibility of the scientist, the technologist, industry and Government, each playing an appropriate part.

The research associations have in this connexion an important potentiality which a number of them have developed very successfuly, namely, the practicability of close collaboration between the technical elements of industry and the scientific staffs of the associations. The technical staffs of industry become closely associated with the progress of the work of projects in which they are interested. There can be developed active collaboration by many avenues; co-operation of member firms in joint researches, conferences, joint committees and frequent contacts between the technical staff of the works and the research station. The intelligence service of the research association alone is a powerful instrument in developing the growth of that research-mindedness which, as the report says, "cannot be achieved until all heads of companies become fully research minded nor until adequate status is accorded to those responsible for research and development in the business". This is done successfully in some industries in Britain and more often in some countries abroad, notahly France. On the other hand, the sciencist should not expect the advocacy of his case to be undertaken by his lay brethren. The attitude to be adopted should be that a worthy eause deserves support.

Noteworthy is the point in this respect that the many achievements of the research associations have been made with only a small fraction of the public support that the Working Party now suggests as being necessary.

In the scheme advocated there could be new problems arising from lack of co-ordination, particularly in the privately inspired research and development contract, while at the same time there could arise a danger of over-rationalization by centralization of civil work at fewer centres. The secret of successful research I believe to be freedom from external interference of the skilled team, for team it must be to-day in much applied research. The largest organizations inevitably become unwieldy in administration. To be able to remain successful they have to resort ultimately to decentralization. There is a point of balance between the extremes of insufficient and overcontrol, which may become a critical issue.

It should of course be realized that the elements of progress are at work all the time. Often the most important are those about which there is least publicity. It is to be hoped that those who are called on to operate the "primingpump' may have the wisdom to guide the stream rightly.

R. J. SARJANT

\title{
THE MELLON INSTITUTE, PITTSBURGH
}

$\mathrm{T}$ HE fiftieth annual report of the Mellon Institute*, covering the year ended February 28,1963 , includes a historical sketch of the development of the Institute written by Dr. E. R. Weidlein.

Dr. Weidlein traces the growth of the Institute and of the industrial fellowship established by Dr. R. K. Duncan at the University of Kansas in 1907, and the Department of Industrial Research he established at the University of Pittsburgh in 1911 with the support of A. W. and R. B. Mellon. The Mellon Institute of Industrial Research and School of Special Industries was first established in 1913 as a part of the University of Pittsburgh, becoming independent as the Mellon Institute of Industrial Research (shortened to Mellon Institute in 1962) in 1927, although it still maintains close co-operation with the University. Functionally a centre for pure and applied research, it is also a clearing house for advanced scientists and a clearing house on specific scientific information. At the end of the year, out of a total personnel of 573,118 held Ph.D.s or other doctorates, 33 were M.Sc.s and 303 were employed in scientific activities, while in addition 49 specialized technicians and craftsmen were mainly concerned with servicing research projects. Operating expenditure on independent and sponsored research amounted to 6.2 million dollars, and 600,000 dollars were also spent on improvement of existing or purchase of new equipment.

In biochemistry, investigations of acid-fast bacteria established that $p$-aminobenzyl alcohol is hydroxylated to $p$-aminophenol, and a new pathway for the metabolism of $p$-aminobenzoic acid has been established chemically by the use of radioactive isotopes. The carboxypeptidase $N$ of human plasma fraction IV - I that activates the hypotensive peptides, bradykinin and kallidin, have been furthor investigated, and a mica replica technique used to examine macromolecules and various polymers of myosin in the electron microscope. In organic chemistry the

- Fiftieth Annual Report of the Mellon Institute for the fiscal year ended February 28, 1963. Pp, 48, (Pittsburgh: Mellon Institute, 1963.) rotational isomerism of some mono- and di-substituted propenes has been investigated by nuclear magnetic resonance spectroscopy, cis, cis, cis-1:4:1-cyclononatriene synthesized from indane in seven steps and also the pseudo-aromatic hydrocarbon, hexaphenylpentalene, and dioxocyanogen, the first difunctional nitriloxide. A multi-state mechanism has been proposed for homogeneous ionic polymerization, studies of the statistical thermodynamics of dilute polymer solutions continued in an examination of the equation of state for solutions of branched polymers, and the light-scattering behaviour of dilute solutions of macromolecules was studied as a func. tion of temperature with a precision photometer having close temperature control, high angular resolution and signal stability. In geochemistry, investigation of the origin of stony meteorites was a major project, and in inorganic chemistry the study of the geometric isomerism of the diphenylalkylphosphine complexes of nickel halides continued; new routes to compounds containing four-membered heterocyclic rings of the type metal $\left.\backslash_{P_{\nearrow}}\right\rangle_{\text {metal }}$ were discovered for nickel, cobalt, iron, manganese and molybdenum, and a unique chemical system capable of carrying molecular oxygen or hydrogen.

In physical chemistry, investigations of the scattering of electrons by molecular gases were initiated and experiments on the vibrational spectra of various compounds completed, while the structures of tetraphenylsilicon and tetraphenyltin were refined by full-matrix 'least-squares' tochnique using anisotropic temperature parameters for all atoms. In radiation chemistry, investigations of the reaction kinetics of halogenated radicals have been extended to the examination of the relative rates of combination and disproportionation of trichloromethyl radicals with various other radicals. In continued investigations of the normal stress effect, the concentrationdependence of solutions of polyisobutylene in cetane has 
been studied in steady-study torsional shearing between two parallel circular disks and between a cone and a disk. Work continued on the development of new methods for obtaining accurate solutions of the molecular Schrödinger equation, and in motal physics tensile deformation investigations were carried out of the close-packed hexagonal copper-germanium phase, while the deformation stacking fault probability was measured in dilute intranoble metal alloys containing up to 5 atomic per cent solute. A list of publications is included.

\section{WHEAT GENETICS}

$\mathrm{T}$ HE second International Wheat Genetics Symposium was held during August 19-24 at the University of Lund, Sweden. The meetings produced a broad survey of many recent advances in knowledge of the genetical architecture of the hexaploid wheat of commerce, Triticum aestivum, and of some of its relatives in the genera Triticum, Aegilops, Agropyron and Secale. Naturally, considerable attention was directed to ways in which the new information could be exploited in the improvement of the crop, but since wheat offers many unique opportunities for genetical work there was no restriction to topics of immediate practical importance.

For example, R. C. F. Macer (Great Britain), R. G. Anderson (Canada), D. R. Knott (Canada) and A. T. Pugsley (Australia) considered the genetic control of re. sistance to stripe rust, leaf rust, stem rust and powdery mildew respectively. In the main, similar patterns of major gene effects are responsible for differences in resistance to all four fungal pathogens, and, as was pointed out by W. Q. Loegering (United States), alleles for resist. ance or susceptibility in the host could be matched by alleles for avirulence or virulence in the fungus, provided the latter had a sexual stage. Basic information of this type has a direct practical value since the recognition of the mode of inheritance greatly facilitates the use of genetically determined resistances in breeding programmes. Moreover, in all these instances the genes for resistance are being isolated, in otherwise equivalent genetic backgrounds giving full susceptibility, so that differential hosts will be available that will permit accurate assessments of the virulence genotypes of pathogens isolated in the field.

The practical importance of incorporating, in wheat, the genetically determined disease resistance of other species was widely accepted during the Symposium. The isolation against the wheat background was reported of single chromosomes from Agropyron giving resistance to stripe, stem and leaf rust by A. Wienhues (Germany), Y. Cauderon (France) and D. R. Knott (Canada), and of one giving resistance to the wheat streak mosaic virus by E. E. Sebesta (United States). R. C. F. Macer (Great Britain) and C. J. Driscoll (Australia) reported that single chromosomes of Secale, isolated against a wheat background, would give resistance to stripe rust and leaf rust. In several instances, use was being made of translocations induced by irradiation to transfer to a wheat chromosome the critical segment of the alien chromosome giving disease resistance.

A remarkable piece of engineering of this type was described by D. R. Knott (Canada). It involved the transfer of $S r 6$, a gene giving stem rust resistance carried on chromosome $2 D$ of the $D$ genome of $T$. aestivum, to $T$. durum, a tetraploid in which chromosome $2 D$ has no homologue. Chromosome $2 D$ was isolated, by backcrossing, against the $T$. durum background and a satisfactory translocation of $S r 6$ to a chromosome of $T$. durum was induced and made homozygous. Not only is a new form of resistance now available at the tetraploid. level, but also the Sr6-carrying tetraploid can be crossed to $T$. aestivum and the gene, in its new position, back-crossed into the hexaploid, and so obtained in four doses. Whether duplication of the gene will show a dose effect that improves disease resistance remains to be seen. A possible alternative to the introduction of alion variation by translocation might be to substitute a pair of alien chromosomes for a pair of wheat chromosomes. This can be achieved by sequences of hybridizations between various aneuploid lines. A. Wienhues (Germany) described the substitution of Agropyron pairs for wheat pairs, and B. C. Jenkins (Canada) the substitution of Secale pairs for wheat pairs. There was some discussion as to whether an alien pair could only be expected to replace a homoeologous wheat pair with which it had a common evolutionary origin, but insufficient evidence is as yet available to clarify the issue.

H. Kihara (Japan) described the production of male sterile forms of wheat by the substitution, by backcrossing, of the wheat nucleus into the cytoplasm of various other species, while J. W. Schmidt and V. A. Johnson (United States) outlined the discovery and use of genes that restore male fertility. This work clearly indicates that the commercial exploitation of hybrid wheat may soon be possible. It is not yet known whether there will be sufficient hybrid vigour to produce an increase in yield adequate to cover the increased cost of seed production - an increase in yield of about 20 per cent is estimated to be necessary. Moreover, many hold that genotypes giving the greater yields should be fixable by selection in the derivatives of hybrids showing heterosis, although this ignores the probable difficulties of breaking some repulsion linkages in a few generations of recombination.

The accumulation of conventional linkage data has been very slow in $T$. aestivum, but $\mathbf{E}$. R. Sears (United States) demonstrated how this could be remedied by using telocentric chromosomes to estimate linkage distances between single major genes and the centromere. In this way some linkage information has already been obtained about chromosomes $3 B$ and $6 B$. Although aneuploidy has been of the utmost value in the genetic analysis of $T$. aestivum, as was demonstrated by R. I. Larson (Canada) and J. Kuspira (Canada), it has been less useful with the tetraploid wheats-presumably because they have fewer duplicate loci and are consequently intolerant of aneuploidy. However, M. Noronha-Wagner and 'T. MelloSampayo (Portugal), working with T. durum (a tetraploid), have been able to hold the nullisomic or monosomic condition for some chromosomes provided that there was compensation for the deficiency by extra dosage of the homoeologue in the other genome. Of interest was the fact that there is some tendency for homoeologous chromosomes to pair at meiosis when in the monosomic-trisomic condition, despite the normally diploid-like meiotic behaviour of the tetraploid wheats.

R. Riley (Great Britain) provided confirmation of the hypothesis that homoeologous meiotic pairing and recombination occur when the restricted pairing specificity, imposed by the activity of chromosome $5 B$, is relaxed. Moreover, the relaxation of specificity permitted the incorporation in wheat chromosomes, by recombination, of segments from the chromosomes of other species in a manner that was otherwise impossible. In a parallel investigation of the $\operatorname{sam} \theta$ system, M. Okamoto (Japan) had selected induced mutants that altered the activity of chromosome $5 B$ in the regulation of meiosis. He indicated the likelihood that such mutants could be stabilized in stocks that would have considerable potential value in practical breeding work.

C. F. Konzak (United States) and R. E. Scossiroli (Italy) considered the value of induced mutations in wheat 